\title{
Inertial sensor and Timed Up and Go test in elderly women with bone demineralization: a reliability and agreement study
}

\author{
Sensor inercial e Timed Up and Go em idosas com desmineralização óssea: estudo de \\ confiabilidade e concordância
}

\begin{tabular}{|c|}
\hline AUTHOR'S \\
\hline Laíla Pereira Gomes da Silva ${ }^{1,2}$ (iD) \\
\hline Maria das Graças Rodrigues de Araújo ${ }^{1}$ (D) \\
\hline André dos Santos Costa ${ }^{2,3}$ (D) \\
\hline Barbara Cristina de Sousa Pedrosa ${ }^{1,4}$ (DD \\
\hline Karla Kristine Dames da Silva ${ }^{3,5}$ (D) \\
\hline Tony Meireles Santos ${ }^{1,2,3}$ (D) \\
\hline $\begin{array}{l}1 \text { Universidade Federal de Pernambuco, Programa } \\
\text { de Pós-graduação em Fisioterapia, Recife, } \\
\text { Pernambuco, Brasil. }\end{array}$ \\
\hline $\begin{array}{l}2 \text { Universidade Federal de Pernambuco, Núcleo } \\
\text { de Investigação em Performance e Saúde, Recife, } \\
\text { Pernambuco, Brasil. }\end{array}$ \\
\hline $\begin{array}{l}3 \text { Universidade Federal de Pernambuco, Programa } \\
\text { de Pós-Graduação Stricto Sensu em Educação } \\
\text { Física, Recife, Pernambuco, Brasil. }\end{array}$ \\
\hline $\begin{array}{l}4 \text { Universidade Federal de Pernambuco, Laboratório } \\
\text { de Imunopatologia Keizo Asami, Programa de Pós- } \\
\text { Graduação em Biologia Aplicada à Saúde, Recife, } \\
\text { Pernambuco, Brasil. }\end{array}$ \\
\hline $\begin{array}{l}5 \text { Instituto Federal do Rio de Janeiro, Rio de Janeiro, } \\
\text { Brasil. }\end{array}$ \\
\hline CORRESPONDING \\
\hline
\end{tabular}

Tony Meireles dos Santos tonymsantos@gmail.com

Departamento de Educação Física. Núcleo de Educação Física e Desportos. Av. Prof. Moraes Rego, 1235 - Cidade Universitária, Recife, Pernambuco, Brasil.

CEP: 50670-901.

\section{DOI}

\section{$10.12820 /$ rbafs. $25 \mathrm{e} 0156$}

\section{(cc) BY}

This work is licensed under a Creative Commons Attribution 4.0 International License.

\begin{abstract}
The study aims to assess: 1) reliability test-retest and error measures of quantitative variables of Timed Up and Go (TUG) testing collected with the inertial sensor wireless Wiva ${ }^{\circledR}$ Science (TUGis), and 2) the agreement of TUGis and the timed method (TUGs) and between the two methods applied to elderly women with osteoporosis and osteopenia. Eighteen elderly women with bone demineralization were enrolled in this study. The time (s) for two executions of the TUG (T1 and T2) was measured with a manual stopwatch by an evaluator and with the inertial sensor attached to the body at the level of the L5 vertebra with remote collection. T1 and T2 were performed with an interval of 1 min. TUG's subtasks were also captured by the inertial sensor. The reliability test-retest and error variables were assessed by the intraclass correlation coefficient (ICC), standard error of measurement $(\mathrm{SEm})$ and minimal detectable change (MDC). The agreement between the averages from the total time of the TUGs and TUGis and between T1 and T2 measured with the sensor and stopwatch were evaluated by the Bland-Altman method. The consistency inside of the subtasks TUGis ranged from substantial to almost complete. The SEm and MDC for TUGis were $1.27 \mathrm{~s}$ and $2.48 \mathrm{~s}$, respectively. The agreement between sensor and stopwatch measurements showed low systematic error. The inertial sensor was reliable in verifying the performance of the TUG and can be a complement for assessing the risk of falls and functional mobility of elderly women with bone demineralization. However, it does not represent an improvement in the exclusive investigation of the total test time.
\end{abstract}

Keywords: Osteoporosis; Ageing; Reproducibility of tests.

RESUMO

O estudo visa avaliar: 1) confiabilidade teste-reteste e medidas de erro das variáveis quantitativas do teste Timed Up and Go (TUG) coletadas com o sensor inercial wireless Wiva ${ }^{\circledR}$ Science (TUGsi) e, 2) a concordância do TUGsi e o método cronometrado (TUGc) e entre os dois métodos aplicados em idosas com osteoporose e osteopenia. Foram recrutadas 18 idosas com desmineralização óssea. O tempo (s) de duas execuçôes do TUG (T1 e T2) foi mensurado com cronômetro manual por um avaliador e com o sensor inercial acoplado ao corpo em nivel da vértebra L5 com coleta remota. T1 e T2 foram executadas com intervalo de 1 min. As subtarefas do TUG também foram captadas pelo sensor inercial. A confiabilidade teste-reteste e erro das variáveis foram avaliados pelo coeficiente de correlação intraclasse (CCI), erro padrão de medida (EPM) e minima mudança detectável (MMD). A concordância entre as médias do tempo total do TUGc e TUCsi e entre T1 e T2 mensuradas com o sensor e cronômetro foram avaliadas pelo método Bland-Altman. $A$ consistência interna das subtarefas do TUGsi variaram entre substancial a quase completa. O EPM e a $M M D$ para o TUGsi foram de 1,27s e 2,48s, respectivamente. A concordância entre medidas do sensor e cronômetro apresentaram baixo erro sistemático. O sensor inercial foi confiável na verificação do desempenho do TUG e pode ser um complemento para avaliação de risco de quedas e mobilidade funcional de idosas com desmineralização óssea. Porém, não representa melhoria na investigação exclusiva do tempo total do teste.

Palavras-chave: Osteoporose; Envelhecimento; Reprodutibilidade dos testes.

\section{Introduction}

The professionals involved in the functional health of the elderly have sought ways to promote independence and to predict problems related to falls ${ }^{1}$. For this reason, the identification of the risk of falls has beco- me important given the prevalence of falling in elderly brazilians $(26.7 \%)^{2}$. Falls are the main mechanism of fractures among the elderly, especially in those with bone demineralization ${ }^{3}$, a common condition in females. Elderly women with osteoporosis are 2.17 times 
more likely to fall and report significantly more falls in one year when compared to elderly women without osteoporosis ${ }^{4}$.

One way of preventing falls is early tracking by assessing physical performance with functional tests ${ }^{5}$. Among these tests, Timed Up and Go (TUG) ${ }^{6}$ ob- $^{-}$ serves abnormalities in balance and functional mobility with a timed approach, quantifying in seconds $(\mathrm{s})$ the accomplishment of the task of getting up from a chair, walking $3 \mathrm{~m}$, going back to the chair and sit again ${ }^{6}$.

More accurate data on the discriminatory ability of TUG in a population at risk of falling have been researched $^{7-10}$, with emphasis on inertial sensors ${ }^{11}$. These electronic devices have accelerometers that allow kinematic assessment of movement and the capture of more detailed quantitative measures at a low cost for the study of static and dynamic balance ${ }^{12,13}$. In addition, they make it possible to observe the subtasks that make up the TUG test and are not captured by the stopwatch in the conventional measurement ${ }^{14}$.

TUG's reliability measured by sensors with accelerometers has been reported in healthy elderly ${ }^{15}$, patients with Parkinson's Disease ${ }^{16}$, in people with vestibular disorders and adults ${ }^{17}$. In all cases cited, the method's reliability was considered satisfactory, with variations in the intraclass correlation coefficient (ICC) between 0.60-0.90. However, there is little information about the reliability of the TUG assessed with inertial sensors in elderly women with low bone mineral density, even being a frequent target population for studies due to their risk of falling.

Given the above, the objective of the study was to analyze the reliability and agreement of the TUG with an inertial sensor in elderly women with bone demineralization, as well as to compare the measurements obtained by the inertial sensor and a manual stopwatch. The hypothesis of the study is that the reliability and agreement of the sensor will be high, since the test measured in a timed manner already has a low systematic error and the given population does not show major fluctuations in movement.

\section{Methods}

This study was approved by the Research Ethics Committee of the Federal University of Pernambuco (Universidade Federal de Pernambuco, UFPE), under opinion No. 1,741,970. The rules of National Health Council (CNS) Resolution No. 466, of September 2012, were respected. We recruited 18 elderly women with bone demineralization between 60-85 years of age, residents of Recife-PE, Brazil, evaluated between September 2016 and February 2017 , in the Laboratory of Kinesiotherapy and Manual Therapeutic Resources (Laboratório de Cinesioterapia e Recursos Terapêuticos Manuais, LACIRTEM) of the Department of Physiotherapy and in the Multipurpose Laboratory of the Department of Physical Education of the Federal University of Pernambuco (Universidade Federal de Pernambuco, UFPE).

The convenience sample consisted of elderly women who already had diagnosed bone demineralization and were enrolled or who had already participated in university extension programs in the aforementioned departments. The extension programs indicated involve diversified activities related to physical activity and quality of life with varied exercises to maintain and/or improve strength, agility, endurance, flexibility.

The World Health Organization (WHO) diagnostic criterion was used for Osteoporosis ( $\mathrm{T}$-score $\leq-2.5$ $\mathrm{SD}$ of a reference population) and Osteopenia ( $\mathrm{T}$-score between -2.5 and $-1 \mathrm{SD})^{18}$. Exclusion criteria for the study were: orthostatism and non-independent gait; use of walking aids due to arthritic, venous and orthopedic conditions; amputations in lower limbs; neurological disorders; visual problems such as blindness or low vision (impaired visual functioning even after treatment and/or correction of common refractive errors); vestibular problems and/or acute pain from any cause.

This is a study of repeated, transversal and analytical measures. After the invitation, explanation of the research and acceptance to participate in the study, by signing the Free and Informed Consent Term (FICT), the collection procedures took place with the completion of an evaluation form for the clinical and anthropometric profile, evaluation of the bone densitometry, in addition to two executions of the TUG $(\mathrm{T} 1, \mathrm{~T} 2)$ with an interval of 1 minute between them, after previous guidance on the test procedure.

The bone mineral densit was measured by the Dual-energy X-ray absorptiometry (DXA) technique with a device Lunar Prodigy Primo (GE Medical Systems Lunar, Wisconsin, United States) by a trained investigator to handle. The daily calibration of the equipment took place prior to the exams and followed the recommendations proposed by the equipment manufacturer. The participants were instructed not to drink alcohol for $48 \mathrm{~h}$ before the test, to avoid the consumption of diuretics 
and caffeine and not to carry metallic objects. The examination was carried out in an air-conditioned room with a temperature of approximately $\approx 21^{\circ} \mathrm{C}$. The acquisition of the images followed the recommendations of the protocol of the equipment manufacturer ${ }^{19}$.

In the application of the TUG, the time of each test in seconds (s) was collected by two instruments: a digital stopwatch by manual activation and the wireless inertial sensor Wiva ${ }^{\circledR}$ Science with remote collection. The average of the $\mathrm{T} 1$ and $\mathrm{T} 2$ runs was measured for each instrument: for the Wiva ${ }^{\circledR}$ Science inertial sensor (TUGis) and for the stopwatch (TUGs). The research description followed the recommendations proposed by the Guidelines for Reporting Reliability and Agreement Studies to report studies of reliability and agreement ${ }^{20}$.

For the clinical profile we collected information on age (years), comorbidities, calcium or vitamin D supplementation, physical activity and falls occurred in the last year were collected. The body mass index (BMI) was calculated from body mass $(\mathrm{kg})$ and height $(\mathrm{m})$, measured with an electronic scale (Filizola ${ }^{\circledR}$, PL-150, Recife-PE, Brazil).

The inertial sensor Wiva ${ }^{\circledR}$ Science is an inertial performance analysis system composed of accelerometer, gyroscope and tri-axial magnetometer. A bluetooth connection is used for data transmission. This wireless sensor is $35 \times 37 \times 15 \mathrm{~mm}$ in size and also captures speed and angular data on trunk mobility. For collection, the device protocol called "Timed Up and Go (TUG)" was selected. The equipment was attached to the body at the level of the lumbar region, the most used site for assessing the risk of falls ${ }^{14,21,22}$. Two evaluators were trained by a team member from the company representing the equipment in the country on how to affix the sensor to the patient's body and operate the device's software.

To perform the Timed up and Go test, a chair was used in an unobstructed area, in front of a distance of $3 \mathrm{~m}$ demarcated by a cone. The participants were instructed to leave the initial position of sedestation, walk, bypass the cone, return and sit down again ${ }^{6}$. The use of light clothes and everyday shoes was advised in order to walk as fast as possible, without running, along the marked path. The inertial sensor attached to the body at lumbar region The duration of each execution of the TUG was measured in the traditional way of collecting test data with a digital timer (Any Time ${ }^{\circledR}$, model XL-010), and by Wiva ${ }^{\circledR}$ Science (KINETEC ${ }^{\circledR}$, Wiva ${ }^{\circledR}$ Science Bologna, Italy), the instrument of interest for this study. After demonstrating the test proce- dure, two attempts at familiarization were granted and were discarded. Two evaluators participated in the collection. A trained physiotherapist fixed the accelerometer in the lumbar region at the level of the L5 vertebra with the aid of the belt that accompanies the sensor, preparing it for capturing data via bluetooth. The other evaluator performed the command for the test and the collection of time in seconds with the stopwatch in the execution of T1 and T2. The remote capture of data by the sensor and manually by the stopwatch was started when the participants removed the trunk from the back of the chair and the end was marked by the return to the initial position.

The use of the sensor makes it possible to capture the subtasks of the TUG, namely: 1) Sit to Stand: the transfer activity during which the subject moves from sitting to standing; 2) Gait forward: walking phase; 3) Turning: the postural transition phase during which the subject rotates 180 degrees to return to the chair; 4) Gait backward: walking phase; 5) Turning-to Sit: a combination of turning transitions and the movement that the individual is standing and going to sit on. With the superposition of these two postural transitions, a single phase is identified. The time for each sub-phase was measured in seconds.

The descriptive presentation of the data was done in proportions, measures of central tendency and dispersion. The normality of the quantitative data was verified with the Shapiro Wilk test. The difference between averages of paired groups was performed with the Wilcoxon signed-rank test. The intraclass correlation coefficient (ICC) of average measures was used, with a mixed two-way model for continuous variables. To interpret the magnitude of the reliability estimators, the following classification was used: 0 (absence), 0-0.19 (poor), 0.20-0.39 (weak), 0.40-0.59 (moderate), 0.600.79 (substantial), and $\geq 0.80$ (almost complete) (23,24 $^{2}$ The Standard Error of Measurement (SEm) was calculated using the equation $\mathrm{SEm}=\mathrm{SD} / \sqrt{ } 2$, considering $\mathrm{SD}$ as the standard deviation of the difference between the pairs of measures ${ }^{25}$. After identifying the SEm value, the Minimum Detectable Change (MDC) was verified by the equation: $\mathrm{MDC}=1.96 * \mathrm{SEm}$, with 1.96 being the score for the confidence interval of a normal distribution $(\mathrm{CI}=95 \%)^{26}$. Agreement was measured using the Bland-Altman method for: 1) the measurements collected (T1 and T2) with theWiva ${ }^{\circledR}$ Science sensor; 2) the collected measurements (T1 and T2) with the manual timer and; 3 ) between the total aver- 
ages of TUGis and TUGs. The plot of the graph shows the mean and the difference of the values matched on the $\mathrm{x}$ and $\mathrm{y}$ axes, respectively, in addition to the limits of agreement (LA), bias value and its standard deviation. Data were treated with Software Statistical Package for the Social Sciences (SPSS), version 19.0 for Windows (SPSS, Inc., Chicago, IL) and Graph Prisma ${ }^{\circledR}$. 5.03. A safety margin of $95 \%$ reliability was used for all tests according to the sample and proposed objectives.

\section{Results}

This study was composed of 18 participants with a mean age of $69.91 \pm 5.34$ years, a mean body mass index (BMI) of $28.75 \pm 4.36 \mathrm{~kg} / \mathrm{m}^{2}$. As for bone demineralization, 11 presented with osteopenia and 7 with steoporosis. Fourteen elderly women mentioned doing some physical activity (150 min of weekly physical activity). Among the comorbidities, 10 mentioned having hypertension, four elderly women had cardiovascular diseases and one reported having diabetes mellitus. $\mathrm{Ca}+$ / Vitamin D supplementation is performed by eight participants. During the last year, the fall event was mentioned by nine elderly women.

Table 1 shows the times in seconds of the components of TUGis and total averages of T1 and T2 of TUGs and TUGis, as well as the reliability indices of repeated measures. The averages of TUGs and TUGis obtained almost complete reliability and the subtasks of TUG are varied between substantial and almost complete reliability.

There was agreement between the $\mathrm{T} 1$ and $\mathrm{T} 2$ tests measured in the TUGis instrumented modality. The visual analysis in Figure 1 shows the absence of bias. Figure 2 shows the agreement assessed in the T1 and T2 measurements measured with the manual stopwatch. Regarding the ways of measuring the TUG, considering

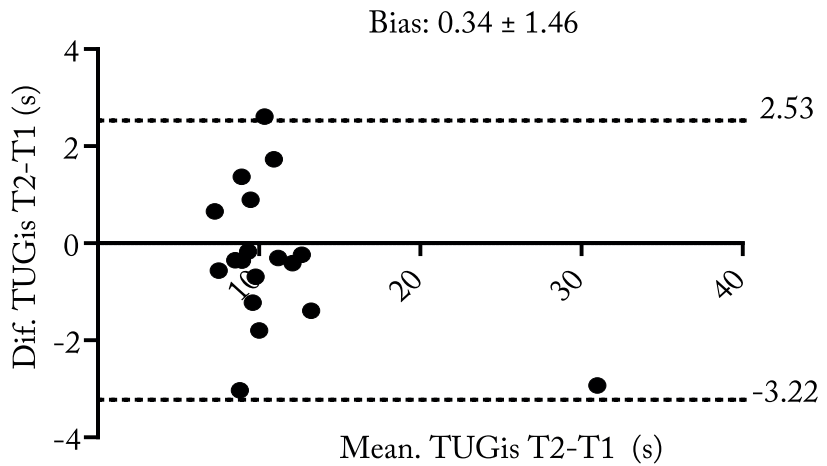

Figure 1-Scatter plots of the Bland Altman method for analyzing the agreement between T1 and T2 measured with the Wiva ${ }^{\circledR}$ Science.

T1 = first execution of the TUG; T2 = second execution of the TUG; TUGis = TUG captured with inertial sensor.

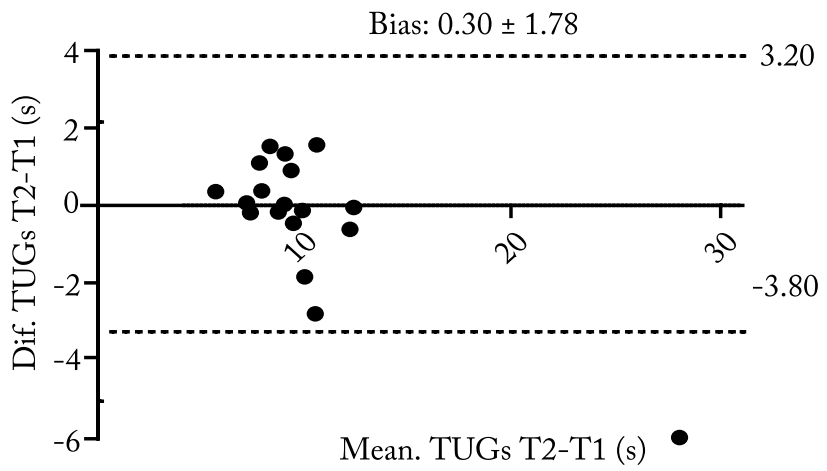

Figure 2 - Scatter plots of the Bland Altman method for analyzing the agreement between T1 and T2 measured with the stopwatch. T1 $=$ first execution of the TUG; T2 = second execution of the TUG; TUGs = TUG measured with manual stopwatch.

the averages of the tests evaluated with the sensor and the stopwatch, low bias was also observed (Figure 3).

In all graphical representations it is possible to identify the presence of an outlier that represents a user with more time than the test execution in relation to the other participants.

Table 1 - Components of TUGis subtasks and total time with TUGs and TUGis.

\begin{tabular}{lccccccccc}
\hline & $\mathrm{T} 1$ & $\mathrm{~T} 2$ & $\mathrm{p}^{*}$ & Difference & $\mathrm{ICC}$ & $\mathrm{CI}_{95 \%}$ & $\mathrm{p}$ & $\mathrm{SEm}$ & $\mathrm{MDC}$ \\
\hline TUGs & $10.55 \pm 5.43$ & $10.25 \pm 4.00$ & 0.861 & $0.34 \pm 1.47$ & 0.96 & $0.90 ; 0.98$ & 0.000 & 1.04 & 2.03 \\
TUGis & $11.26 \pm 5.58$ & $10.91 \pm 4.96$ & 0.276 & $0.30 \pm 1.79$ & 0.98 & $0.94 ; 0.99$ & 0.000 & 1.27 & 2.48 \\
Sitting-to stand & $2.11 \pm 1.40$ & $1.69 \pm 0.90$ & 0.107 & $0.42 \pm 1.20$ & 0.63 & $0.81 ; 0.86$ & 0.018 & 0.85 & 1.66 \\
Gait Forward & $2.85 \pm 1.61$ & $2.63 \pm 1.46$ & 0.338 & $0.22 \pm 0.81$ & 0.92 & $0.80 ; 0.97$ & 0.000 & 0.57 & 1.12 \\
Turning & $1.23 \pm 0.71$ & $1.24 \pm 0.58$ & 0.459 & $-0.01 \pm 0.34$ & 0.82 & $0.54 ; 0.93$ & 0.000 & 0.24 & 0.47 \\
Gait Backward & $2.79 \pm 1.72$ & $2.61 \pm 1.16$ & 0.239 & $0.19 \pm 0.70$ & 0.93 & $0.84 ; 0.97$ & 0.000 & 0.50 & 1.97 \\
Turning to sit & $2.54 \pm 1.07$ & $2.71 \pm 1.53$ & 1.000 & $-0.17 \pm 1.02$ & 0.82 & $0.54 ; 0.93$ & 0.000 & 0.72 & 1.41 \\
\hline
\end{tabular}

T1 = first execution of the TUG; T2 = second execution of the TUG; $\mathrm{p}^{*}=\mathrm{p}$-value ICC $=$ intraclass correlation coefficient; Sem = standard error of measurement; $\mathrm{MDC}=$ minimum detectable change; TUGis = TUG captured with inertial sensor; TUGs = TUG captured with a stopwatch. Note $=p^{*}$ value referring to the Wilcoxon signed-rank test. 


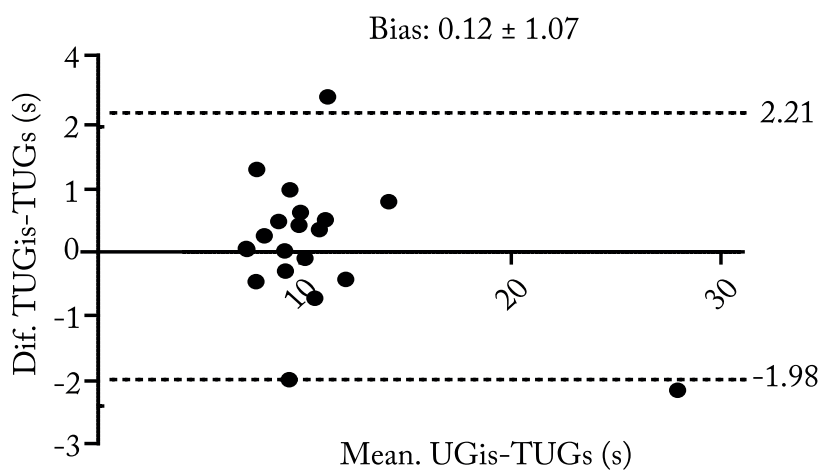

Figure 3 - Scatter plots of the Bland Altman method for analyzing the agreement between $\mathrm{T} 1$ and $\mathrm{T} 2$ measured with the stopwatch and with the inertial sensor Wiva ${ }^{\circledR}$ Science.

TUGis = TUG captured with inertial sensor; TUGs = TUG captured with stopwatch.

\section{Discussion}

This study investigated the test-retest reliability and agreement of repeated measurements taken with the sensor inertial wireless Wiva ${ }^{\circledR}$ Science while performing the TUG by elderly with bone demineralization. The data collected with the sensor were reproducible and demonstrated high reliability, both between collections with different measurement methods, and in the TUG test subtasks captured by the sensor. In addition, the study of the measurement error showed low values of SEm and MDC on the use of the electronic device for both total times and subtasks.

The reliability of time and components of the instrumented TUG is have been used as complementary measures in predictive fall discrimination for healthy adults and elderly ${ }^{15,22}$ and also individuals with diseases or disabilities ${ }^{21,27-29}$. Despite the variable number of subtasks captured by sensors with accelerometers, which identify kinematic events in studies on the topic, our results corroborate data obtained in adults that point out that the components of the TUG that involve the activity with a chair during the test obtained lower values of $\mathrm{ICC}^{11}$. Only the transfer from sitting to rising showed a greater measurement error $(\mathrm{SEm}=$ $0.85)$ and lower reliability $(\mathrm{ICC}=0.63$; IC 95\%) in relation to the other phases of TUGis.

All subtasks that make up the TUG test obtained SEm lower than $1 \mathrm{~s}$ and MDC around 2s. The MDC of the total times of T1 and T2 evaluated by the sensor and the stopwatch showed time around 1.12 to $2.4 \mathrm{~s}$, which is close to variations between 1.5 and $2 \mathrm{~s}$ observed in the literature with motion sensors, stopwatches and optoelectronic markers ${ }^{11}$. There are some hypotheses related to the measurement error such as differences in the instructions given by the evaluator or differences in the subjects' behavior over time, which can denote different gait speeds during repeated test execution ${ }^{16}$.

This may suggest that the variability between the participants in the repetition of the test may be the main source of error instead of the technique itself ${ }^{11}$. Another hypothesis, related to the device, may be related to accuracy. The difference between marking the start of the test and the start of the participant's movement according to his reaction time could originate this difference ${ }^{16}$.

The plotting of Bland Altman graphs indicates agreement between the conventional method and the instrument with low bias. This bias was attributed to the evaluator's precision in defining the start and end of the test $\mathrm{t}^{16}$. In addition to this factor, the poor alignment of the sensor and the friction generated between the clothing and skin of the evaluated participants have also been reported as a reason for the error and, finally, may reflect the agreement between the two forms of measurements ${ }^{15}$.

As it is a small instrument and at a lower cost, it could be an alternative option considering that the "gold standard" for the analysis of TUG subtasks involves capturing images by motion analysis ${ }^{11,16}$. In this situation, capturing images requires a system of visual movement analysis that would make it difficult to measure the test outside well-equipped environments, such as laboratories and research centers.

Even without having standardized time references for instrumented TUG, these findings can guide a more qualitative approach to the functionality of elderly women with bone demineralization in order to prevent falls. It must be considered that the good performance of the TUG depends on the integration and time of the various subtasks necessary to meet the general demands of the task ${ }^{30}$. Thus, the use of sensors allows a more detailed view of the gestures that is not allowed in the evaluation of the total test time.

A study of the test's subtasks in the community's elderly showed that the variables that involved transfers and turning on the axis itself, both related to trunk mobility, were the most accurate in classifying the risk of falling ${ }^{22,28}$. Approaching these results to clinical practice, there is an indication that the use of these subtasks can more specifically identify which gestures require more time to be performed by the elderly women with bone demineralization and possibly a higher risk of failure due to the difficulty of performing it.

In the comparison of the two methods, our data included only time measurements in seconds. Even with 
low measurement errors, it would not in itself justify the replacement of the timed measurement method, since it would not represent a necessary improvement in the evaluation. Thus, the use of these devices in the evaluation of TUG time is shown to be feasible, but do not stand out from the conventional way of measuring with stopwatches, when considering the exclusive evaluation of the total test time.

Future studies may also include measures of angulation and speed in the execution of the subtasks of the TUG in order to bring new information on strategies and failures in carrying out the test to ascertain the functional health and motor control of elderly women with bone demineralization, the target audience of this study. The small sample size and presentation only of test-retest reliability create a limitation to our study. Intra- and inter-evaluator analyses are recommended, as well as the investigation of more accelerometer fixation points as a result of the research on the reliability of the device in question.

It was concluded that the use of the inertial sensor was reproducible and reliable for the evaluation of TUG in elderly women with bone demineralization, despite not being superior to the manual stopwatch for checking the total time of execution of the TUG. The investigation of the subtasks of the TUG test represents a possibility of complement in the assessment of risk of falls and functional mobility of elderly women with bone demineralization.

\section{Conflict of interest:}

The authors declare no conflict of interest.

\section{Authors' contributions}

Each author contributed individually and completely to the development of the manuscript. Silva LPG, contributed to the design, work design, statistical analysis, data collection, review and intellectual content of the study, agreed to be held responsible for all aspects of the work to ensure that any matter related to the integrity or accuracy of any of his parties is properly investigated and resolved. Santos TM, contributed to the design, work design, statistical analysis, data collection, review and intellectual content of the study, in addition to the final approval of the manuscript version to be published. Araújo MGR, contributed to the design, work design, data collection, review and intellectual content of the study. Costa AS, contributed to the conception, design of the work, statistical analysis, data collection, review and intellectual content of the study. Silva KKD, contributions to the design, review and intellectual content of the study, in addition to the final approval of the version of the manuscript to be published. Pedrosa BCS, contributed to the design of the work project, statistical analysis, data collection, review and intellectual content of the study, review and intellectual content of the study.

\section{Acknowledgments}

This work was carried out with the support of the National Council for the Improvement of Higher Education Personnel - Brazil (CAPES).

\section{References}

1. Macedo C, Gazzola JM, Najas M. Síndrome da fragilidade no idoso: importância da fisioterapia. Arq Bras Ciências da Saúde. 2008;20;33(3):177-84.

2. Siqueira FV, Facchini LA, Silveira DS, Piccini RX, Tomasi E, Thumé E, et al. Prevalence of falls in elderly in Brazil: a countrywide analysis. Cad Saude Publica. 2011;27(9):1819-26.

3. Ambrose AF, Cruz L, Paul G. Falls and Fractures: A systematic approach to screening and prevention. Maturitas. 2015;82(1):85-93.

4. Silva RB, Costa-Paiva L, Morais SS, Mezzalira R, Ferreira NO, Pinto-Neto AM. Predictors of falls in women with and without osteoporosis. J Orthop Sports Phys Ther . 2010;40(9):582-8.

5. Singh DKA, Pillai SGK, Shahar S, Tan ST, Tai CC. Association between physiological falls risk and physical performance tests among community-dwelling older adults. Clin Interv Aging. 2015;10;1319.

6. Podsiadlo D, Richardson S. The Timed "Up \&amp; Go": A Test of Basic Functional Mobility for Frail Elderly Persons. J Am Geriatr Soc [Internet]. 1991;39;2;142-8.

7. Schoene D, Wu SM-S, Mikolaizak AS, Menant JC, Smith ST, Delbaere K, et al. Discriminative ability and predictive validity of the timed up and go test in identifying older people who fall: systematic review and meta-analysis. J Am Geriatr Soc. 2013;61(2):202-8.

8. Hasegawa $\mathrm{N}$, Shah V V, Carlson-Kuhta P, Nutt JG, Horak FB, Mancini M. How to Select Balance Measures Sensitive to Parkinson's Disease from Body-Worn Inertial Sensors-Separating the Trees from the Forest. Sensors. 2019;19(15):3320.

9. Greene BR, McManus K, Redmond SJ, Caulfield B, Quinn CC. Digital assessment of falls risk, frailty, and mobility impairment using wearable sensors. npj Digit Med. 2019;2(1).

10. Sun R, Sosnoff JJ. Novel sensing technology in fall risk assessment in older adults: A systematic review. BMC Geriatr. 2018;18(1).

11. Beyea J, McGibbon CA, Sexton A, Noble J, O'Connell C. Convergent Validity of a Wearable Sensor System for Measuring Sub-Task Performance during the Timed Upand-Go Test. Sensors (Basel). 2017; 23;17(4):934.

12. O'sullivan M, Blake C, Cunningham C, Boyle G, Finucane C. Correlation of accelerometry with clinical balance tests in older fallers and non-fallers. Age Ageing. 2009;38(3):308-13.

13. Cultrera P, Pratelli E, Petrai V, Postiglione M, Zambelan G, Pasquetti P. Evaluation with stabilometric platform of balance disorders in osteoporosis patients. A proposal for a diagnostic protocol. Clin Cases Miner Bone Metab. 2010;7(2):123-5. 
14. Montesinos L, Castaldo R, Pecchia L. Wearable Inertial Sensors for Fall Risk Assessment and Prediction in Older Adults: A Systematic Review and Meta-Analysis. IEEE Trans Neural Syst Rehabil Eng. 2018;(99):1.

15. Galán-Mercant A, Barón-López JJ, Labajos-Manzanares MT, Cuesta-Vargas AI. Reliability and criterion-related validity with a smartphone used in timed-up-and-go test. Biomed Eng Online. 2014;13(1):1-11.

16. Van Lummel RC, Walgaard S, Hobert MA, Maetzler W, Van Dieën JH, Galindo-Garre F, et al. Intra-Rater, Inter-Rater and Test-Retest Reliability of an Instrumented Timed Up and Go (iTUG) Test in Patients with Parkinson's Disease. Stamatakis EA, editor. PLoS One. 2016;21;11(3).

17. McGrath D, Greene BR, Doheny EP, McKeown DJ, De Vito G, Caulfield B. Reliability of quantitative TUG measures of mobility for use in falls risk assessment. In: 2011 Annual International Conference of the IEEE Engineering in Medicine and Biology Society [Internet]. IEEE; 2011. p. 466-9. Available from: http://www.ncbi.nlm.nih.gov/ pubmed/22254349.

18. WHO. WHO Global Report on Falls Prevention in Older Age. Community Health. 2007.

19. Re-imagined H. Lunar Prodigy Primo. 2008.

20. Kottner J, Audige L, Brorson S, Donner A, Gajewski BJ, Hróbjartsson A, et al. Guidelines for Reporting Reliability and Agreement Studies (GRRAS) were proposed. Int J Nurs Stud [Internet]. 2011 Jun;48(6):661-71.

21. Howcroft J, Kofman J, Lemaire ED. Review of fall risk assessment in geriatric populations using inertial sensors. J Neuroeng Rehabil [Internet]. 2013;10(1):91.

22. Drover D, Howcroft J, Kofman J, Lemaire E. Faller Classification in Older Adults Using Wearable Sensors Based on Turn and Straight-Walking Accelerometer-Based Features. Sensors. 2017; 7;17(6):1321.
23. Shrout PE, Fleiss JL. Intraclass correlations: uses in assessing rater reliability. Psychol Bull. 1979 Mar;86(2):420-8.

24. Miot HA. Análise de concordância em estudos clínicos e experimentais. J Vasc Bras. 2016 Jun;15(2):89-92.

25. Hopkins WG. Measures of reliability in sports medicine and science. Sports Med. 2000;30(1):1-15.

26. Stockbrugger BA, Haennel RG. Validity and reliability of a medicine ball explosive power test. J strength Cond Res. 2001/12/01. 2001 Nov;15(4):431-8.

27. Vervoort D, Vuillerme N, Kosse N, Hortobágyi T, Lamoth CJC. Multivariate analyses and classification of inertial sensor data to identify aging effects on the timed-Up-andGo test. PLoS One. 2016;11(6):1-17.

28. Zakaria NA, Kuwae Y, Tamura T, Minato K, Kanaya S. Quantitative analysis of fall risk using TUG test. Comput Methods Biomech Biomed Engin. 2013;5842:37-41.

29. Nguyen HP, Ayachi F, Lavigne-Pelletier C, Blamoutier M, Rahimi F, Boissy P, et al. Auto detection and segmentation of physical activities during a Timed-Up-and-Go (TUG) task in healthy older adults using multiple inertial sensors. J Neuroeng Rehabil . 2015 11;12(1):36.

30. Weiss A, Mirelman A, Giladi N, Barnes LL, Bennett DA, Buchman AS, et al. Transition Between the Timed up and Go Turn to Sit Subtasks: Is Timing Everything? J Am Med Dir Assoc. 2016;17(9):864.e9-864.e15.

Recebido: $16 / 10 / 2019$

Aprovado: 03/11/2020

\section{Quote this article as:}

Silva LPG, Araújo MGR, Costa AS, Pedrosa BCS, Silva KKD, Santos TM. Inertial sensor and Timed Up and Go test in elderly women with bone demineralization: a reliability and agreement study. Rev Bras Ativ Fís Saúde. 2020;25:e0156. DOI: 10.12820/rbafs. 25e0156 